\title{
JUURNAL.RU
}

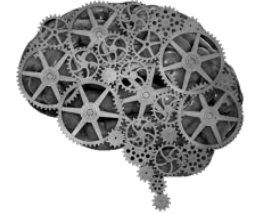

COMPANY GROUP "INTELLEKT"

Салынов И. А. Рязанский государственный радиотехнический университет Рязань, Россия

doi: 10.18411/lj2016-6-4-06

\section{Оптимизация электронно-оптической системы рентгеновской трубки в САПР «Фокус»}

Целью работы является максимальное уменьшение диаметра фокусного пятна на аноде рентгеновской трубки 0,32П3-160 для повышения интенсивности её рентгеновского излучения.

Острофокусная рентгеновская трубка 0,32П3-160 предназначена для использования в медицинских и промышленных аппаратах для рентгеновской дефектоскопии [1]. Её конструкция состоит из катода косвенного накала, фокусирующей системы в виде одной электронной линзы (модулятор и пролётная труба) и отражательного анода. Электронно-оптическая система трубки, смоделированная в программе «Фокус», изображена на рис.1.

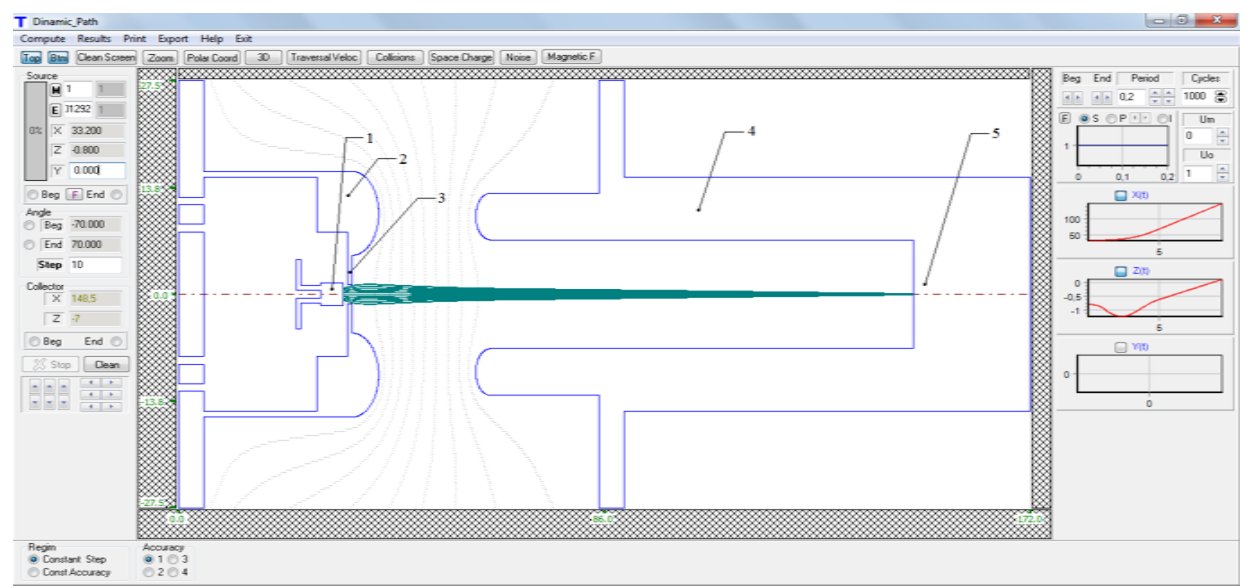

Рис. 1. Электронно-оптическая система рентгеновской трубки 0,32П3-160; 1 - Катод, 2 - Модулятор, 3 - Диафрагма, 4 - Пролётная труба, 5 - Анод

Под действием термоэлектронной эмиссии электроны вылетают с катода.

Часть электронов с торцевой поверхности катода пролетает через диафрагму, 
образуя основной поток электронов, который фокусируется электронной линзой в центр поверхности анода (фокусное пятно). Остальные электроны с краёв торца и с боковой поверхности попадают на диафрагму с модулятором и в процессе создания рентгеновского излучения не участвуют, т.к. их начальные траектории сильно отличаются от траекторий электронов основного потока и этим нарушают фокусировку.

Моделирование электронно-оптической системы рентгеновской трубки было произведено в программе «Фокус», предназначенной для моделирования аксиально-симметричных электронно-оптических систем устройств электронной и ионной оптики [2]. Были промоделированы траектории только торцевых, пролетевших через диафрагму электронов, т.е. электронов, участвующих в создании рентгеновского излучения на аноде (рис. 2).

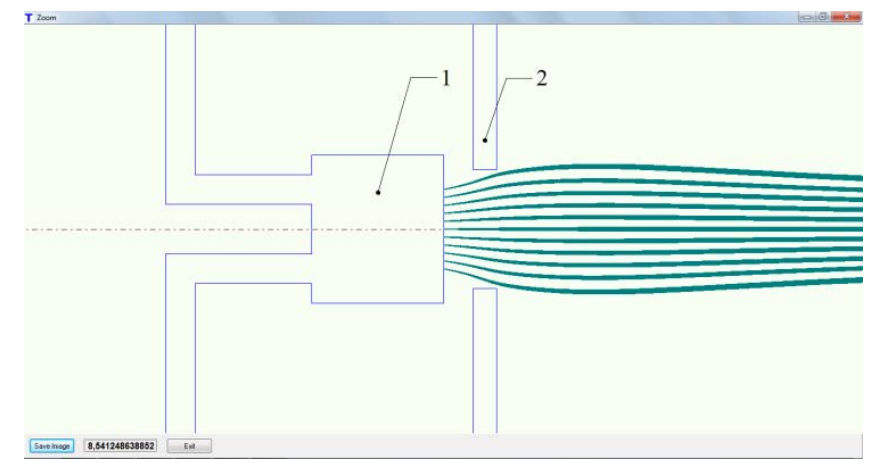

Рис. 2. Моделирование траекторий электронов основного потока; 1 - Катод, 2 - Диафрагма

Изначально в рентгеновской трубке 0,32П3-160 диаметр фокусного пятна составлял 0,8 мм [1]. В процессе оптимизации были получены следующие результаты: (указанный шаг - минимальный шаг с видимыми изменениями)

- Уменьшение диаметра отверстия диафрагмы с 3 мм до 2,4 мм (шаг 0,1 мм) уменьшило фокусное пятно до 563 мкм. Дальнейшее уменьшение диаметра значительно увеличило фокусное пятно.

- Увеличение внутреннего диаметра пролётной трубы с 14 мм до 15 мм (шаг 1 мм) уменьшило фокусное пятно до 443 мкм. Дальнейшее увеличение диаметра уменьшало фокусное пятно на 1-2 мкм. 
Уменьшение внутреннего диаметра пролётной трубы ниже 14 мм растягивает фокусы разных лучей по оси трубки.

- Уменьшение расстояния между катодом и анодом с 124 мм до 114 мм (шаг 1 мм) уменьшило фокусное пятно до 264 мкм. Дальнейшее уменьшение расстояния значительно увеличило фокусное пятно.

- Уменьшение толщины диафрагмы с 1 мм до 0,8 мм (шаг 0,1 мм) уменьшило фокусное пятно до 218 мкм. Дальнейшее уменьшение толщины диафрагмы значительно увеличило фокусное пятно.

- Уменьшение длины пролётной трубы с 85,5 до 80,5 мм уменьшило фокусное пятно на 1 мкм. Увеличение выше 85,5 мм или уменьшение ниже 80,5 мм (шаг 5 мм) увеличивало диаметр фокусного пятна на 10мкм.

- Уменьшение расстояния между катодом и диафрагмой (шаг 0,1 мм) значительно увеличивало диаметр фокусного пятна, а увеличение уменьшает плотность потока электронов, но не изменяет фокусное пятно.

Выводы: В данной работе удалось оптимизировать конструкцию электронно-оптической системы рентгеновской трубки 0,32П3-160 с помощью компьютерного моделирования в САПР «Фокус». Первоначальный диаметр фокусного пятна, равный 0,8 мм, был уменьшен до 218 мкм. Исходя из результатов моделирования, можно заключить, что наиболее важными геометрическими параметрами электронно-оптической системы являются толщина диафрагмы и диаметр отверстия в ней. Расстояние между катодом и анодом и внутренний диаметр пролётной трубы меньше влияют на траектории электронов, а остальные геометрические параметры почти не влияют на них. 


\section{Литература:}

1. Бочков В.Д., Бочков Д.В., Дягилев В.М., Васильев И.В., Панов П.В., Терешин В.И. и Ушич В.Г. Мощные газоразрядные и вакуумные приборы нового поколения для импульсной энергетики, электрофизики и нанотехнологий. Современное состояние. Опыт работы на международном рынке // XI Международный семинар по проблемам ускорителей заряженных частиц посвященного памяти профессора В.П.Саранцева, 07 11 сентября 2015 г. пансионат ОИЯИ «Дубна» г. Алушта, Крым.

2. Трубицын А.А. Программа «Фокус» моделирования аксиальносимметричных электронно-оптических систем: алгоритмы и характеристики // Прикладная физика. 2008. - №2. - С. 56-62. 